\title{
Central Lumpectomy with Resection of the Nipple-Areolar Complex
}

National Cancer Institute

\section{Source}

National Cancer Institute. Central Lumpectomy with Resection of the Nipple-Areolar

Complex. NCI Thesaurus. Code C137848.

Breast-sparing surgery that removes diseased tissue from the central part of the breast, including the nipple and areola. 